UNDERGRADUATE RESEARCH IN NATURAL AND CLINICAL SCIENCE AND TECHNOLOGY (URNCST) JOURNAL Read more URNCST Journal articles and submit your own today at: https://www.urncst.com

\title{
2021-2022 STEM Sustainability Case Competition: Synthetic Biology
}

Michael Hamilton, BScBiomed Student [1]*, Reece Cowan, BScBiomed Student [1], Kartikay Pabbi, BScBiomed Student [1], Sarah Matta, BScBiomed Student [1], Madison Packer, BScBiomed Student [1], Lyndsey de Guzman, BSc Biomed Student [1], Ammarah Nakhuda, BScNeur Student [2]

[1] Department of Biomedical Sciences, University of Guelph, Guelph, Ontario, Canada N1G 2W1

[2] Department of Psychology, University of Guelph, Guelph, Ontario, Canada N1G 2W1

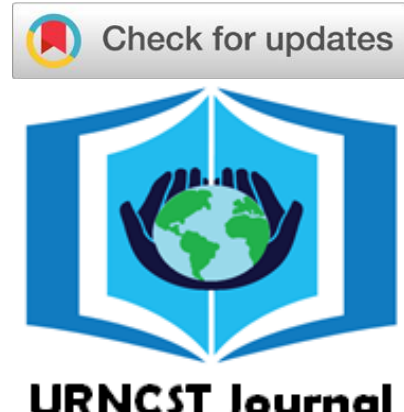

"Research in Earnest"

*Corresponding Author: ssgsa@uoguelph.ca

Note: Correction added after original version published on February 18, 2022. We regret any inconvenience caused.

\begin{abstract}
The STEM Sustainability Case Competition is an annual research case competition hosted by undergraduate students from the STEM Students Guelph Support Association (SSGSA). The mission of this competition is to provide University of Guelph undergraduate students with an opportunity to develop their own research proposal while gaining valuable experience in innovative thinking and critical research analysis. Each year students, in teams of up to three, are paired with an experienced mentor to develop and present a novel research proposal aligning with the competition's theme. During the competition, students are taught fundamental principles outlining nine various lab techniques that they could write about in their proposal. The theme this year was creating solutions for global challenges impacting areas within synthetic biology. In the 2021-2022 STEM Sustainability Case Competition 70 total participants submitted abstracts to be adjudicated, and we present the Top 15 winning submissions to be read by you (accessed on our website: https://www.stemstudentsguelphsupportassociation.com/) in our competition abstract booklet. We hope you enjoy reading this year's best abstract submissions and continue to take part in the growing SSGSA community as we strive to encourage interest in novel scientific research while providing an outlet to approach real-world problems creatively.
\end{abstract}

Keywords: STEM Sustainability Case Competition; SSGSA; abstract submissions; synthetic biology; undergraduate; STEM; research; University of Guelph

Table of Contents

STEM Sustainability Case Competition Abstracts

pg. A01-A09

\section{Conference Abstracts}

Note: These abstracts have been reproduced directly from the material supplied by the authors, without editorial alteration by the staff of the URNCST Journal. Insufficiencies of preparation, grammar, spelling, syntax, and usage are the authors.

\section{$\underline{\text { STEM Sustainability Case Competition Abstracts }}$}

Eliminating HIV-1 using CRISPR-Cas9 and LASER ART in combination

Noah Whitelaw, BSc BIOM [1], Janet Tang, BSc BIOM [1], Raakin Rishad, BSc BIOM [1]

[1] Department of Biomedical Sciences, University of Guelph, Guelph, Ontario, Canada N1G 2W1

Human immunodeficiency virus (HIV-1) is a retrovirus that causes an autoimmune disease linked to the depletion of CD4+T cells. HIV-1 enters the host cell through various coreceptors conditional to the variant, where infection eventually leads to CD4+T cell cytolysis, which is cell death caused by bursting of the cell. Currently, HIV-1 is incurable and can only be regulated with antiretroviral therapy (ART), inhibiting the spread of infection through restricting viral replication. Treatments such as long-acting slow-effective release ART (LASER ART) are effective by increasing viral restriction factors, by elevating drug levels at reservoir sites. Whereas CRISPR inhibits the expression of Tat and Rev proteins. This study will investigate the efficacy of combination therapy using LASER ART to target latent reservoir sites resulting in the suppression 
UNDERGRADUATE RESEARCH IN NATURAL AND CLINICAL SCIENCE AND TECHNOLOGY (URNCST) JOURNAL Read more URNCST Journal articles and submit your own today at: https://www.urncst.com

of plasma viremia. In unison, CRISPR and LASER ART will effectively target reservoir sites and cut HIV-1 proviral DNA from the host entirely. Additionally, CRISPR-Cas9 will be used to excise HIV-1 proviral DNA from the host genome using AAV9 for delivery and eliminate latent HIV-1 provirus. Mice will be humanized by grafting human CD34+ HSC and confirmed by flow cytometry. Four sets of HIV-infected rats will be used in the study: a CRISPR-Cas9 treatment group, LASER ART treatment group, combined treatment group, and a control group. Combination therapy has demonstrated levels of success in rodent trials in the removal of latent infectious reservoirs. Removal of integrated proviral DNA is carried out by in vivo excision of HIV-1 subgenomic DNA fragments; treated rats with combined therapy exhibit no latent reservoirs of HIV-1. Conversely, rodent groups treated exclusively with LASER ART or CRISPR-Cas9 show no evidence of elimination of HIV-1. This evidence presents a foundation for further research and the possibility of non-human primate trials to develop a cure.

Investigating the etiology of sea star wasting disease through metagenomic analysis using BLAST Samantha McGuinness, BSc NEUR [1], Kathryn Austin, BSc MFB [2], Emily Gibbons, BSc MBG [3]

[1] Department of Psychology, University of Guelph, Guelph, Ontario, Canada N1G 2W1

[2] Department of Integrative Biology, University of Guelph, Guelph, Ontario, Canada N1G 2W1

[3] Department of Molecular and Cellular Biology, University of Guelph, Guelph, Ontario, Canada N1G 2W1

Sea star wasting disease (SSW) is a condition that affects asteroids globally. Most significantly, in 2013, there was a mass mortality of over 20 species in the Northeastern Pacific. The etiology of SSW is unknown, however there are 3 theories: viral infection, microbial action on organic matter $(\mathrm{OM})$ causing depleted $\mathrm{O}_{2}$ at the animal-water interface, or a combination of the two as a syndrome. This study will investigate if SSW is a syndrome through determining whether water from a tank with an OM-induced wasting Pisaster ochraceus will induce SSW of a P. ochraceus in tanks with different OM treatments. The water from the affected tank will be piped into two other tanks, both with a non-infected $P$. ochraceus. The three tanks are categorized as a tank with affected P. ochraceus induced by OM, a tank with sterilized OM, and a tank without OM. The onset of SSW will be measured, and the presence and composition of previously identified microbes and will be tested for in tissues and water columns using the bioinformatic techniques BLAST. It is predicted that the tanks without OM will have a lower occurrence of SSW because the conditions allow viruses and not microbes to survive. The study allows for evaluation of whether SSW is a result of an interaction between viral pathogens and microbial action. After assessing levels of pathogenicity and microbial growth in each of the tanks, the tank showing the highest number of visible star sickness could be further analyzed in a future study. Since the etiology of SSW remains unknown, it is crucial to assess the relationship and significance of both viruses and microbes to find possible solutions. Although evidence supports many potential causing agents, little research has studied a possible interaction between viruses and microbes in SSW.

Utilization of CRISPR-Cas9 system and agrobacterium in coat protein to aid crops in developing geminivirus resistance Kajisha Vijayakumar, BSc FOOD [1], Iman Andrea Niyokindi shima, BSc BMPH [2]

[1] Department of Food Science, University of Guelph, Guelph, Ontario, Canada N1G 2W1

[2] Department of Physics, University of Guelph, Guelph, Ontario, Canada N1G 2W1

Geminiviruses have caused millions of dollars in losses in the Indian bean and African cassava industries, causing global food shortages. Geminiviruses are DNA viruses with a small genome and a few encoded proteins. In recent years, clustered regularly interspaced short palindromic repeats (CRISPR) have been investigated to try to develop crop resistance to these viruses. Cas9 (a site-specific DNA endonuclease) and a synthesized single guide RNA (sgRNA) form the CRISPR-Cas9 machinery. Cas9 is directed to its genomic target region by sgRNA and cleaves the phage through two nuclease domains. Cas9-nickases increase cleaving accuracy and permit larger deletions. According to the literature, CRISPR can be used to delete plant susceptibility (S) genes in order to generate disease resistance in crops. However, no particular $S$ genes for the geminivirus have been discovered. A proposed solution is to target the coat proteins AV1/V1, the only structural proteins of the geminivirus. These proteins are crucial to their function as they are responsible for the shuttling of the viral DNA to and from the nucleus, and binding of ssDNA for effective replication. We hypothesize that CRISPR-Cas 9 could be delivered along with Cas9-nickases (to increase efficacy) and agrobacterium to the affected crops. Agrobacterium is a pathogen that creates tumours in plant cells, but is also used for transgenics due to its ability to transfer DNA. The expected effect of the insertion of T-DNA from the agrobacterium is a mutation in the coat protein, which will damage the coat protein and render it inactive.Without this structural protein, viral infection would not be effective, making the geminivirus useless. This would benefit the agricultural industry by preventing the infection of billions of crops, resulting in increased productivity and a reduction in global food crisis.

Hamilton et al. | URNCST Journal (2022): Volume 6, Issue 2

DOI Link: https://doi.org/10.26685/urncst.351

Page A2 of A9 
UNDERGRADUATE RESEARCH IN NATURAL AND CLINICAL SCIENCE AND TECHNOLOGY (URNCST) JOURNAL Read more URNCST Journal articles and submit your own today at: https://www.urncst.com

\author{
Glyphosate-induced effects on heterotrophic and autotrophic bacteria \\ Leah Van Raalte, BSc BIOS [1] \\ [1] College of Biological Science, University of Guelph, Guelph, Ontario, Canada N1G 2W1
}

To accommodate growing demand for food, modern farmers have turned to pesticides and herbicides. Roundup is a common glyphosate-based herbicide used worldwide and is sprayed on entire fields. Glyphosate inhibits the shikimic acid pathway in weeds, but also in soil bacteria. Many microorganisms need the shikimic acid pathway to produce aromatic amino acids like tryptophan, which is needed for acetyl-CoA production. Acetyl-CoA is vital to cellular functions, including polyhydroxyalkanoate production, which helps the cells survive under stress, and allows for carbon and energy storage. This carbon can come from carbohydrates (heterotrophic bacteria) or environmental $\mathrm{CO}_{2}$ (autotrophic). Glyphosate-based products disrupt vital bacterial processes significantly. To examine the effects of glyphosate on specific types of bacteria, three species will be examined including: heterotrophic Achromobacter piechaudii, Rhodopseudomonas palustris (autotrophic and heterotrophic), both grown in a soil sample, and autotrophic Cyanobacteria grown in pond-like conditions. Glyphosate will be applied in increasing quantities, to multiple samples of each bacterium. Treated and untreated (control) bacteria samples will be comparatively evaluated using gas and liquid chromatography to determine acetyl-CoA and polyhydroxyalkanoate content. Bacteria which receive higher doses of glyphosate are expected to have lower amounts of polyhydroxyalkanoate and acetyl-CoA. Rhodopseudomonas palustris is expected to be least affected by glyphosate, due to its versatility in energy sources followed by Cyanobacteria, since it is dependent only on photosynthesis. Achromobacter piechaudii will fare the worst, because it is fully dependent on Acetyl-CoA production to carry out the Krebs cycle. Observing glyphosate's effect on different types of bacteria offers a better understanding of the impact of Roundup overuse on soil health and can help to guide what restrictions should be placed on its use in the future. Because carbon capture is particularly important in modern society, glyphosate's effects on bacterial carbon capture has serious implications for environmental health.

In vivo CRISPR-Cas9 gene editing of the MTHFD2 gene in CD4+ T-cells to reduce symptoms of multiple sclerosis Alexander J. Botschner, BSc MICR [1], William A. Botschner, BSc MICR [1], Ariana Z. Zargar, BSc BIOM [2]

[1] Department of Molecular and Cellular Biology, University of Guelph, Guelph, Ontario, Canada N1G 2 W1

[2] Department of Biomedical Sciences, University of Guelph, Guelph, Ontario, Canada N1G 2W1

Multiple sclerosis (MS) is a common neurodegenerative autoimmune disorder, in which over-stimulation of the immune system stimulates the action of CD4+ T-cells. This contributes to elevated levels of glutamate, causing demyelination in nerve cell axons. It is evident that a specific gene, metabolism enzyme methylenetetrahydrofolate dehydrogenase 2 (MTHFD2) plays a role in T-cell function and inhibiting this gene has been shown to be effective in treating MS in animal models. This study will be the first to investigate the use of CRISPR-Cas9 in vivo gene editing to decrease demyelination in those diagnosed with MS by inhibiting the MTHFD2 gene in CD4+ T-cells. We will administer a myelin basic protein peptide fragment to two groups of 2D2 TCR mice in order to induce the animal model for MS, Experimental Autoimmune Encephalomyelitis (EAE), while a third group will be used as the control. After induction of EAE, mRNA encoding CRISPR-Cas9 and guide RNA (gRNA) proteins will be injected into the bloodstream of one of the EAE treatment groups using the injection method outlined by Gillmore et al. (2021). The injected mRNA will be contained by lipid nanoparticles coated with Natalizumab, a monoclonal antibody that targets integrins located on T lymphocytes. This will allow the mRNA to target the CD4+ T-cells, allowing the gRNA to direct the CRISPR-Cas9 to the MTHFD2 gene and induce mutations in the CD4+ T-cells. We will then use the magnetization transfer technique to assess demyelination in MS lesions. We expect an increased magnetization transfer ratio to indicate evidence of a reduced occurrence of demyelination in MS lesions. To conclude, this study will possibly demonstrate the use of this novel in vivo CRISPR-Cas9 gene-editing method to reduce symptoms of MS. Further research should be done to investigate the efficacy of this method in human trials.

Hamilton et al. | URNCST Journal (2022): Volume 6, Issue 2

Page A3 of A9

DOI Link: https://doi.org/10.26685/urncst.351 
UNDERGRADUATE RESEARCH IN NATURAL AND CLINICAL SCIENCE AND TECHNOLOGY (URNCST) JOURNAL Read more URNCST Journal articles and submit your own today at: https://www.urncst.com

\author{
A novel approach to bioremediation of microplastics in agricultural soil using pleurotus ostreatus \\ Emma Veres, BSc BIOS [1] \\ [1] College of Biological Science, University of Guelph, Guelph, Ontario, Canada N1G 2W1
}

Microplastic pollution has been found in agricultural soil and can be linked to the degradation of crop and soil quality which results in a myriad of negative environmental and health concerns. Recent evidence suggests that when microplastics degrade into nanoplastics, they may enter plant roots, become embedded in crops, and cause health implications for consumers. However, over $2.1 \%$ of Canadian plastic production is used for agriculture, of which $40 \%$ is plastic mulch, used to insulate and protect crops and soil. Pleurotus ostreatus fungi could be used to mitigate this problem due to its ability: to degrade plastic, to be converted into synthetic plastic, and to amend soil. This study will explore the use of an alternative plastic mulch synthesized from Pleurotus ostreatus as a potential bioremediation strategy to reduce plastic pollution, while also improving soil health in agricultural soils. To synthesize the alternative mulch, fungal mycelium will be grown in agar, incubated in a liquid bath, then washed in Choline chloride: Ethylene glycol. The efficacy of the mycelium mulch will be assessed via an ex-situ modified land farming approach where microplastic polluted soil from five farms across Ontario will be used to grow cabbage in two treatments (mycelium mulch or plastic mulch additions) and one control (no mulch added). Lab trials will be conducted for three months and the abundance of soil microplastics, crop root and shoot size, as well as $\mathrm{CO}_{2}$ flux will be measured weekly. The addition of the mycelium mulch is expected to maintain or increase crop productivity, reduce soil microplastic concentration, and increase soil carbon sequestration. The results of this study will provide a novel strategy for bioremediation of microplastic pollution in agricultural soils. This data will have implications for food safety, sustainable agriculture, as well as the utilization of fungi as a synthetic biology bioremediation tool.

Treatment of late-stage prostate cancer using Fc3TSR normalized vasculature to deliver chimeric antigen receptor (CAR)-T cells programmed with qPCR isolated gene

Jan Eichhorn, BSc BIOM [1], Duncan Petrik, BSc BIOM [1], Finn Eichhorn, BSc HK [2]

[1] Department of Biomedical Sciences, University of Guelph, Guelph, Canada N1G 2W1

[2] Department of Human Health and Nutritional Sciences, University of Guelph, Guelph, Canada N1G 2 W1

Prostate cancer is the 4 th most common cancer in Canada and comprises $33 \%$ of all cancers in men. While precision surgery and targeted radiation therapy has resulted in a decline in prostate cancer deaths in the past decades, there are still a significant number of men who experience persistent disease that are refractory to current therapies. The presence of an immunosuppressive environment, and inhospitable tumor microenvironment decrease the success of these treatments. We will investigate a novel approach to normalize the tumor vasculature by enhancing the uptake and efficacy of chimeric antigen receptor (CAR)-T cells targeting prostate cancer specific antigens. Fc3TSR can potently normalize the tumor vasculature, reduce interstitial fluid pressure, and increase the uptake of a variety of therapies. Prostate specific antigens PSMA CAR-T cells have been developed and will be used in our study. Additionally, we will perform RNA sequencing using qPCR on prostate tumors and normal prostate gland to identify novel differentially-expressed cell surface antigens that are indicative of prostate cancer cells. We will utilize an orthotopic, syngeneic mouse model of prostate cancer in which RM9 cells will be injected into the prostate gland of C57BL-6 mice. Tumors will be allowed to develop untreated for 2 weeks at which time mice will remain untreated (controls) or be treated with Fc3TSR for 2 weeks to induce vascular normalization. Mice will then be infused intravenously with $2.5 \times 10^{6}$ CAR-T cells expressing individual target antigens. Two weeks after treatment, tumors will be collected, measured, weighed and immunostained for the presence of $\mathrm{T}$ cells. We anticipate that Fc3TSR will normalize tumor vasculature and increase the uptake of CAR-T cells. Fc3TSR in combination with CAR-T cells is expected to result in an additive anti-tumor effect and will offer a novel and effective strategy for the treatment of prostate cancer.

\author{
Attenuation of opioid withdrawal symptoms and respiratory depression by means of combined regimen of \\ mitragynine and methadone \\ Isabelle Paradis, BSc BIOM [1], Madeline Vukovic, BSc BIOM [1], Nicole Harder, BSc BIOC [2] \\ [1] Department of Biomedical Sciences, University of Guelph, Guelph, Ontario, Canada N1G 2W1 \\ [2] Department of Molecular and Cellular Biology, University of Guelph, Guelph, Ontario, Canada N1G 2W1
}

While much media coverage has focused on deaths caused by COVID-19 during the pandemic, less publicized was the $60 \%$ increase in opioid overdoses from 2019-2020 (Science Table COVID-19 Advisory for Ontario, 2021). Respiratory depression facilitated by opioid agonists play a role in $71.4 \%$ of overdose deaths. A component of the mitragynine alkaloid,

Hamilton et al. | URNCST Journal (2022): Volume 6, Issue 2

Page A4 of A9

DOI Link: https://doi.org/10.26685/urncst.351 
UNDERGRADUATE RESEARCH IN NATURAL AND CLINICAL SCIENCE AND TECHNOLOGY (URNCST) JOURNAL Read more URNCST Journal articles and submit your own today at: https://www.urncst.com

7-hydroxymitragynine, acts as an opioid agonist and does not exhibit the respiratory depressant effect of methadone, an agonist used to decrease withdrawal symptoms and agonize the $\mu$-opiate receptors engaged by opioid use. We want to examine the effects of combining a lower dose of methadone with mitragynine (MG) to decrease opioid withdrawal symptoms and respiratory depression. Liquid chromatography will be used to extract MG from leaves of the kratom plant (Mitragyna speciosa), and determine the purity of the samples with the target purity $>95 \%$. Sprague-Dawley rats will be used to test the regimens of methadone, MG, and the combined low dose of methadone plus MG. All groups will be given adequate doses of morphine to achieve antinociception every 12 hours for 4 days, and at the same time administered either saline $(\mathrm{CON})$, methadone (E1), MG (E2), or the combined dose (E3). This would be followed by the administration of antagonist Naloxone and the monitoring of withdrawal symptoms (diarrhea, teeth chattering, etc.) and respiratory depression over a 7 day period. We expect that E1 and E2 rats will show reductions in withdrawal symptoms (and E2 in respiratory depression) in comparison to the untreated group, and E3 rats will show the greatest reduction in withdrawal symptoms and less respiratory depression than E1. This provides a basis for human clinical trials investigating safer treatments for opioid addiction and further alternative therapies to combat the opioid crisis.

The removal of HLA - B27 gene mutation through CRISPR-Cas9

Sukhjot Pooni, BSc NEUR [1], Athena Austen, BSc NEUR [1]

[1] Department of Psychology, University of Guelph, Guelph, Ontario, Canada N1G 2 WI

Ankylosing spondylitis (AS), a prevalent type of spondyloarthropathy, is a chronic inflammatory autoimmune disease where the human leukocyte antigen HLA-B27 presents pathogenic T cells with peptides incriminated in arthritis. It can further cause the formation of B27 homodimers (B272), which on the cell surface serve as pathogenic role through binding with natural killer family receptors and KIR's (killer Ig-like receptors) and/or LILRs (leukocyte Ig-like receptors). Patients with AS typically describe the feeling of dull pain or stiffness coming from their lower back and symptoms generally worsen over time. Using the technique of CRISPR-Cas9 may be promising in preventing those that are HLA-B27 positive, from developing ankylosing spondylitis. This study will utilize two groups of Wistar rats: a control group and a genetically altered group. Genetically modifying the expression of HLA-B27 will cause rats carrying this transgene to develop AS similar pathogenesis, leading to ankylosing pathology. They are expected to experience bony ankylosis of the spine as seen in progressed AS. CRISPR-Cas9 technology will be utilized to alter the expression of the HLA - B27 gene and entirely remove the mutation causing AS on the HLA - B27 gene. By using this method to target and delete the mutations on HLA-B27 genes found on white blood cells, the risk for AS is virtually eliminated altogether. Ankylosing spondylitis affects mainly men and adults which is why in a male-dominated, aging population, a treatment for this disease is crucial.

\section{Chromatography and PCR examined as diagnosis techniques for cystic fibrosis and pseudomonas aeruginosa infections Kevin Magda, BSc MCB [1], Nada Al-Kishtaini, BSc BIOM [2] \\ [1] Department of Molecular and Cellular Biology, University of Guelph, Guelph, Ontario, Canada N1G 2 W1 \\ [2] Department of Biomedical Sciences, University of Guelph, Guelph, Ontario, Canada N1G 2WI}

Cystic fibrosis $(\mathrm{CF})$ is a hereditary autosomal recessive disease caused by mutations in the CF transmembrane conductance regulator (CFTR) gene found on the long arm of human chromosome 7, region q31-32. CFTR is a chloride channel, responsible for membrane potential stabilization and signal transduction in epithelial cells. CFTR protein defection is caused by several mutations that affect its normal function. As a result, chloride transport at the epithelial cell surface is impeded, causing symptoms such as sputum production, difficulty breathing, and fever. Currently, CF diagnosis is based on chloride concentration quantification from sweat samples using single-channel ion chromatography/high-performance liquid chromatography. Patients with CF possess a chlorine concentration 10 times higher than non-affected persons. In this sense, a dual-channel system can reduce the time of analysis and therefore, a faster diagnosis. Pseudomonas aeruginosa is a pathogenic bacterium that takes advantage of pulmonary symptoms caused by $\mathrm{CF}$ and produces chronic endobronchial infections which can be lethal. Conventionally, bacterial density of collected sputum samples is used to diagnose the presence of the pathogen. However, combining a two-step quantitative polymerase chain reaction (qPCR) could produce an earlier diagnosing of $P$. aeruginosa by a gain of 8 months. If bacterial density is $<730 \mathrm{CFU} / \mathrm{mL}$, oprL qPCR alone is used; if not, oprL qPCR combined with gyrB/ecfX qPCR is used instead. If one of the two-step qPCR procedures confirms the existence of $P$. aeruginosa, aggressive antibiotic therapy can be considered to handle this colonization and impairs infection. Through

Hamilton et al. | URNCST Journal (2022): Volume 6, Issue 2

Page A5 of A9

DOI Link: https://doi.org/10.26685/urnest.351 
UNDERGRADUATE RESEARCH IN NATURAL AND CLINICAL SCIENCE AND TECHNOLOGY (URNCST) JOURNAL Read more URNCST Journal articles and submit your own today at: https://www.urncst.com

these considerations, chromatography and PCR techniques can be optimized as diagnosis methods of CF and endobronchial infections, allowing faster and more accurate treatment strategies that could avoid long-term antibiotics use and the development of resistance strains.

\section{Attenuating the allergic response through the upregulation of FoxP3 and KLFR2 transcription factors using CRISPR-Cas9} Trinita J. Hamilton, BSc BIOM [1], Nicole M. Ramirez-Gaston, BSc BIOM [1], Akeba, Mendes, BSc BTOX [1] [1] Department of Biomedical Sciences, University of Guelph, Guelph, Ontario, Canada N1G

Allergies are a chronic disease involving an abnormal immune response to a non-infectious substance. Follicular helper $\mathrm{T}\left(\mathrm{T}_{\mathrm{FH}}\right)$ cells encounter these antigens and induce the release of Immunoglobulin $\mathrm{E}$ (IgE) antibodies, resulting in a sensitization to the substance and induction of the adaptive immune response. Follicular regulatory $\mathrm{T}$ ( $\left.\mathrm{T}_{\mathrm{FR}}\right)$ cells counteract the activity of $\mathrm{T}_{\mathrm{FH}}$ cells by reducing the levels of IgE production, causing high $\mathrm{T}_{\mathrm{FH}}$ cell activity and low $\mathrm{T}_{\mathrm{FR}}$ cell activity in patients. High $\mathrm{T}_{\mathrm{FH}}$ cell activity is associated with low expression of the KLFR2 transcription factor, whereas low $\mathrm{T}_{\mathrm{FR}}$ cell activity is attributed to low expression of the FoxP3 transcription factor. Currently, there is limited research on balancing the $\mathrm{T}_{\mathrm{FH}}: \mathrm{T}_{\mathrm{FR}}$ ratio by upregulating these transcription factors. Increasing the expression of these transcription factors requires the use of CRISPR activation, in which a dead Cas9 fused with the Supernova tagging (SunTag) system is guided to a target site by sgRNA, promoting the recruitment of activator proteins to the site. This study will investigate whether the allergic response can be suppressed by balancing the $\mathrm{T}_{\mathrm{FH}}: \mathrm{T}_{\mathrm{FR}}$ ratio using CRISPR-Cas9 to increase the expression of FoxP3 and KLFR2. A control group and a treated group of $\mathrm{C} 3 \mathrm{H} / \mathrm{HeJ}$ mice will be sensitized to peanuts by administering $80 \mathrm{mg}$ peanut extract. The treatment group will then be genetically edited with SunTag array-dCas9 fusion system to induce the expression of FoxP3 and KLFR2. Serum samples of the spleen will be measured using enzyme linked immunosorbent assay (ELISA) to compare the $\operatorname{IgE}$ and histamine production between the groups. The treated group is expected to show reduced levels of IgE and histamine, demonstrating a suppressed allergic reaction. Further research in gene editing using human clinical trials allows for better understanding of the $\mathrm{T}_{\mathrm{FH}}: \mathrm{T}_{\mathrm{FR}}$ ratio, providing advancements in immunotherapy and treatments for severe allergic reactions.

Investigating the effect of obesity on the expression of proteins associated with induced CYP1A1 and CYP1A2 enzyme synthesis in vivo

Junpyo Lee, BSc BIOM [1], Hyeyun Yang, BSc BIOM [1]

[1] Department of Biomedical Sciences, University of Guelph, Guelph, Ontario, Canada N1G 2W1

Obesity is characterized by excessive body fat combined with a body mass index above or equal to 30 and is linked to a higher risk of cancer. Obesity is associated with an increase in CYP1A1 and CYP1A2 expression. CYP1A1/1A2 are phase I metabolism enzymes that are predominantly found in the liver, which metabolize xenobiotics such as polycyclic aromatic hydrocarbons (PAH) commonly found in charbroiled foods. As PAH is metabolized by CYP1A1/1A2, reactive metabolites are produced, which become carcinogenic upon accumulation. Overexpression of CYP1A1/1A2 in obesity leads to the accumulation of these cancer-inducing metabolites. The mechanism of CYP1A1/1A2 overexpression in obesity is poorly understood. This study investigates the effect of obesity on the expression of proteins associated with CYP1A1/1A2 synthesis in rat hepatocytes. The expression of aryl hydrocarbon receptor (AhR), Hsp90 (heat shock protein-90), p23 (cell cycle regulator), AIP (AhR interacting protein), and ARNT (AhR nuclear translocator) will be investigated. AhR is an upregulating transcription factor of CYP1A1/1A2 that is kept inactive with Hsp90, p23, and AIP complex in a normal state. As PAH enters hepatocytes, the AIP complex interacts with PAH leading to AhR release, nuclear translocation, and DNA binding as a heterodimer with ARNT, resulting in the expression of CYP1A1/1A2 enzymes. The expression levels of AhR, Hsp90, p23, AIP complex and ARNT will be determined pre and post oral exposure to PAH using rtPCR in control and obese Sprague Dawley rat hepatocytes. Obese rats are expected to have reduced gene expression of Hsp90, p23, AIP proteins and an increase in AhR and ARNT expression levels compared to control. This information further elucidates the mechanism of CYP1A1/1A2 enzyme synthesis in obesity. This information could be used to justify the development of a drug targeting AhR or associated proteins to prevent the accumulation of carcinogenic PAH metabolites in obese patients.

Hamilton et al. | URNCST Journal (2022): Volume 6, Issue 2

Page A6 of A9

DOI Link: https://doi.org/10.26685/urncst.351 
UNDERGRADUATE RESEARCH IN NATURAL AND CLINICAL SCIENCE AND TECHNOLOGY (URNCST) JOURNAL Read more URNCST Journal articles and submit your own today at: https://www.urncst.com

\author{
Vascular endothelial growth factor upregulation by means of CRISPR-Cas9 to accelerate healing of rotator cuff \\ injury in rats \\ Ashlee Chan, BSc BIOM [1], Vanessa Nunez, BSc HK [2] \\ [1] Department of Biomedical Sciences, University of Guelph, Guelph, Ontario, Canada N1G 2W1 \\ [2] Department of Human Health and Nutritional Sciences, University of Guelph, Guelph, Ontario, Canada N1G 2W1
}

Rotator cuff injuries, commonly caused by degeneration and trauma, are among the most common tendon injuries. Typically, tendon injuries have a limited capacity for healing due to poor vascularization. Gene therapy presents a promising way to enhance healing capacity by delivering growth factors to the injured site through manipulating the expression of gene products. The vascular endothelial growth factor (VEGF) is a protein that becomes active almost immediately after tissue injury and facilitates processes involved in inflammation, cell proliferation, and remodelling. The main role of VEGF in healing ligaments is to regulate angiogenesis. Angiogenesis is the formation of new blood vessels, allowing for the delivery of oxygen and nutrients to tissues, which are essential to recovery. Using a rat model $(\mathrm{n}=30)$, healthy rats will undergo a gait analysis assessment to measure stride length, step width, contact intensity, stance, and speed. A partial thickness rotator cuff defect will be created by scratching the surface of the supraspinatus tendon using a scalpel. Half of the rats will be randomly selected to receive a saline placebo treatment, while the other half will receive the CRISPR-Cas9 treatment. A dCas-9activator fusion that targets the promoter region of VEGF-A will be administered via local injection into the supraspinatus to temporarily increase the expression of VEGF, and hence, angiogenesis. Healing rates will be quantified weekly over a 12 week period by repeating the gait analysis assessment. Once the rats achieve greater than $90 \%$ of the pre-injury results of gait analysis, they will be deemed fully healed. Rats that receive the CRISPR-Cas9 treatment are expected to heal at a faster rate. Based on research by Bell et al., mice and human rotator cuffs are anatomically similar, making these findings potentially useful for human patients.

Repression of IRF8 gene to treat acute myeloid leukemia using CRISPRi Alisa Baxter, BSc BIOM [1], Fatima Askary, BSc BIOS [2], Abina Thomas, BSc BIOS [2]

[1] Department of Biomedical Sciences, University of Guelph, Guelph, Ontario, Canada N1G 2WI

[2] Collage of Biological Science, University of Guelph, Guelph, Ontario, Canada, N1G 2W1

CRISPR interference (CRISPRi) can be utilized to treat metastatic cancers by reducing the expression of specific regulators that control the tumour's progression. CRISPRi technology will provide a novel and efficient lifesaving treatment for cancer patients that are unresponsive to traditional treatment methods such as chemotherapy. As an example, acute myeloid leukemia (AML) is the most common type of leukemia in adults, with an overall survival rate of merely $30 \%$. This study will investigate the validity of CRISPRi as a safe gene therapy option to treat acute myeloid leukemia by repressing ZMYND8, a core regulatory protein that controls the progression of AML and can be measured by IRF8 expression. For this study, in vitro work will be done in leukemia human cell lines that mimic AML conditions. Cells will be treated with a CRISPRi system that represses the expression of ZMYND8. Expression levels of ZMYND8 and IRF8 will be monitored via RT-qPCR and the proliferation of myeloblasts will be assessed. Then NSG mice will be used to conduct a follow-up in vivo experiment. The NSG mice will be given an intrafemoral injection of primary AML cells and inoculated with CRISPRi through lentiviral transduction. After treatment with the CRISPRi system, ZMYND 8 and IRF 8 expression levels will be quantified, and the rats will be monitored for cancer progression. Genetic repression of ZMYND 8 using CRISPRi will demonstrate therapeutic potential in treating AML human cancer affected cells and rats with leukemia. This study will explore the unrealized benefits of diverse CRISPR systems that can be potentially utilized in human subjects. The use of CRISPRi in AML affected patients can be further extended to other types of cancer, after finding the specific genes that are causing them.

Preventing harlequin ichthyosis in humanized model mice using CRISPR-Cas9

Onome Adese, BSc BPCH [1], Madeleine O'Connor, BSc BIOM [2]

[1] Department of Chemistry, University of Guelph, Guelph, Ontario, Canada, N1G 2W1

[2] Department of Biomedical Sciences, University of Guelph, Guelph, Ontario, Canada, N1G 2W1

Harlequin ichthyosis (HI) is a rare congenital autosomal disease that affects about 1 in 300,000 newborns, most of whom do not survive the neonatal period. This severe form of ichthyosis is caused by frameshift or nonsense mutations in the ATP binding cassette A12 (ABCA12) gene found on chromosome $2 \mathrm{q} 35$. ABCA12 is responsible for coding the ATP binding cassette $(\mathrm{ABC})$ transporter proteins that are essential for transporting lipids in keratinocytes and for normal lamellar body formation. These mutations affect $A B C A 12$ expression, resulting in abnormal vesicle formation in the cytoplasm of

Hamilton et al. | URNCST Journal (2022): Volume 6, Issue 2

Page A7 of A9

DOI Link: https://doi.org/10.26685/urncst.351 


\section{UNDERGRADUATE RESEARCH IN NATURAL AND CLINICAL SCIENCE AND TECHNOLOGY (URNCST) JOURNAL}

Read more URNCST Journal articles and submit your own today at: https://www.urncst.com

corneocytes and dysfunctional lamellar granules. In this research proposal, we aim to develop a gene therapy procedure to prevent individuals from developing HI. First, humanized immunodeficient mouse NOD-Rag1-/-IL2RgammaC-null embryos possessing the mutated $A B C A 12$ gene will be generated using in vitro fertilization. Embryos will go through preimplantation genetic diagnosis using polymerase chain reaction (PCR) to determine which embryos contain the mutation. Then, during the CRISPR-Cas9 procedure, Cas9 mRNA will be microinjected into the embryos to target $A B C A 12$. Next, the co-opting regulation bypass repair approach will be used to add the correct genetic sequence between the promoter region and the mutated region of the $A B C A 12$ gene. To minimize off-target effects, terminator sequences will be inserted upstream of the mutation and downstream of the promoter region to stop the rest of the mutated gene from being used in the process. Finally, PCR will be used to confirm the ABCA12 edition by comparing new and original DNA sequences. It is expected that this approach will prevent $\mathrm{HI}$ development by providing the embryo with the correct gene sequence to encode functional $\mathrm{ABC}$ protein, thus enabling normal growth of the epidermis. If successful, this methodology could provide a basis for future clinical applications and be used to treat other genetic disorders underlain by $\mathrm{ABC}$ mutations such as cystic fibrosis.

\section{Conflicts of Interest}

The authors declare that they have no conflict of interests. These authors include: Michael Hamilton, Reece Cowan, Kartikay Pabbi, Sarah Matta, Madison Packer, Lyndsey de Guzman and Ammarah Nakhuda.

\section{Authors' Contributions}

MH: Co-President and founder of the SSGSA, drafted the SSGSA Synthetic Biology competition case package, reviewed the abstract submissions and ensured that they adhered to correct formatting standards, and gave final approval of the version to be published.

RC: Co-President of the SSGSA, drafted the SSGSA Synthetic Biology competition case package, reviewed the abstract submissions and ensured that they adhered to correct formatting standards, and gave final approval of the version to be published.

SM: Drafted the SSGSA Synthetic Biology competition case package, reviewed the abstract submissions and ensured that they adhered to correct formatting standards, and gave final approval of the version to be published.

MP: Drafted the SSGSA Synthetic Biology competition case package, reviewed the abstract submissions and ensured that they adhered to correct formatting standards.

LG: Reviewed the abstract submissions and ensured that they adhered to correct formatting standards.

KP: Reviewed the abstract submissions and ensured that they adhered to correct formatting standards.

AN: Reviewed the abstract submissions and ensured that they adhered to correct formatting standards.

\section{Acknowledgements}

We would like to recognize the STEM Sustainability Case Competition Organizational Committee for their hard work and contributions in ensuring that this competition was a complete success. The members of this dedicated team include; Thomas Habib as the SSGSA Case Competition Branch Coordinator; Cassidy Laub as the Logistics Coordinator; Mikaela Kassar and Jessica Howe as the Marketing Co-Chairs; Lily Skakavac as the Case Competition Volunteer Coordinator; and Diana May as the Fundraising and Development Chair. Additionally, we would like to thank the 6 professors who judged the first-round abstract submissions, the 24 graduate students who have dedicated their time as mentors throughout the competition, and the 70 University of Guelph undergraduate students who competed in our first competition. Without all those mentioned this competition would not be made possible, and we look forward to building on this year's success in the upcoming years of the STEM Sustainability Case Competition.

\section{Funding}

Both monetary and non-monetary:

Student Life Enhancement Fund Committee

Central Student Association

University of Guelph College of Biological Science

University of Guelph Ontario Veterinary College

University of Guelph College of Engineering and Physical Sciences

University of Guelph Ontario Agricultural College

College of Biological Sciences Student Council 

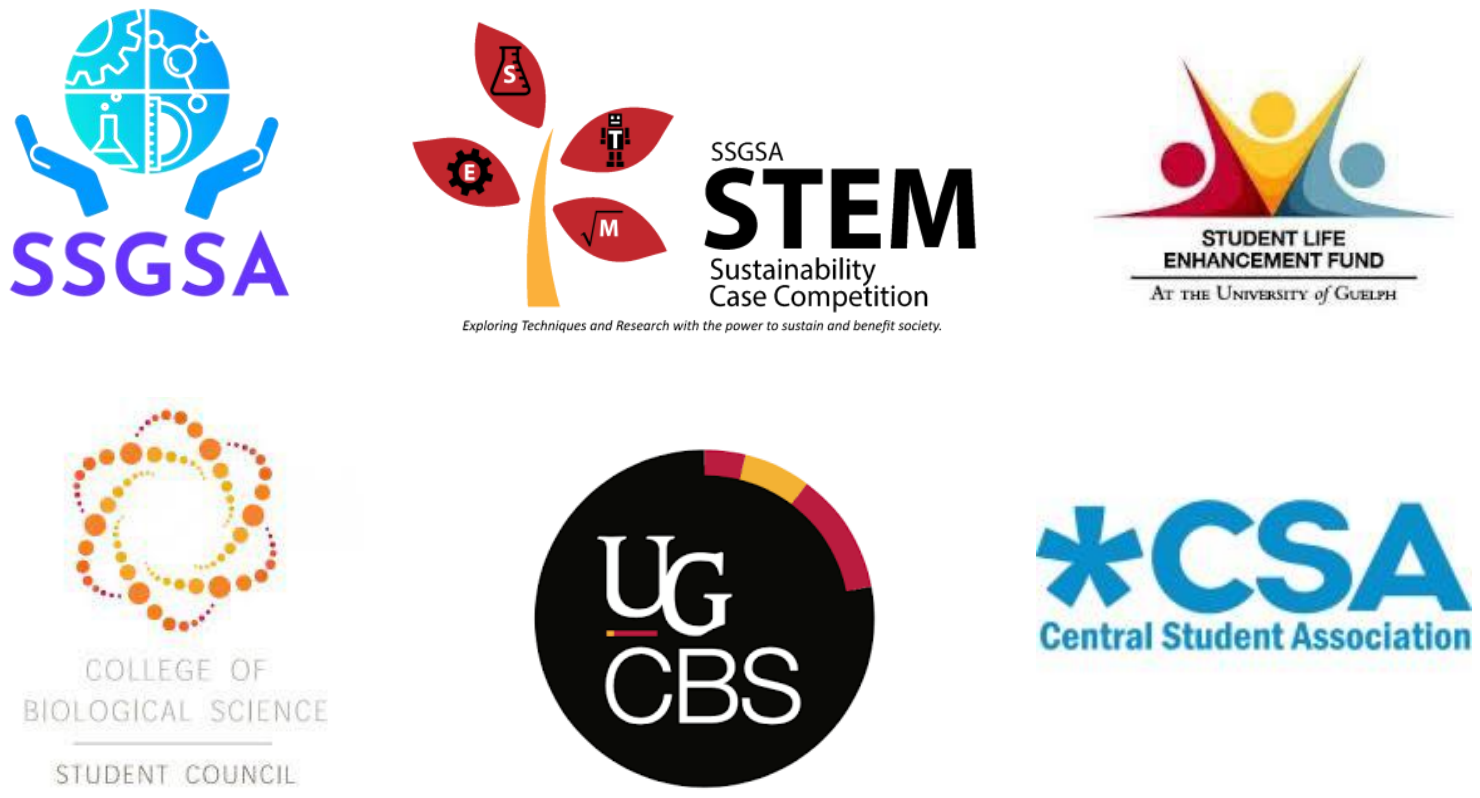

\section{Article Information}

Managing Editor: Jeremy Y. Ng

Article Dates: Received Feb 01 22; Published Feb 1822

\section{Citation}

Please cite this article as follows:

Hamilton M, Cowan R, Pabbi K, Matta S, Packer M, de Guzman L, Nakhuda A. 2021-2022 STEM Sustainability Case Competition: Synthetic biology. URNCST Journal. 2022 Feb 18: 6(2). https://urncst.com/index.php/urncst/article/view/351 DOI Link: https://doi.org/10.26685/urncst.351

\section{Copyright}

(C) Michael Hamilton, Reece Cowan, Kartikay Pabbi, Sarah Matta, Madison Packer, Lyndsey de Guzman, Ammarah Nakhuda. (2022). Published first in the Undergraduate Research in Natural and Clinical Science and Technology (URNCST) Journal. This is an open access article distributed under the terms of the Creative Commons Attribution License (https://creativecommons.org/licenses/by/4.0/), which permits unrestricted use, distribution, and reproduction in any medium, provided the original work, first published in the Undergraduate Research in Natural and Clinical Science and Technology (URNCST) Journal, is properly cited. The complete bibliographic information, a link to the original publication on http://www.urncst.com, as well as this copyright and license information must be included.
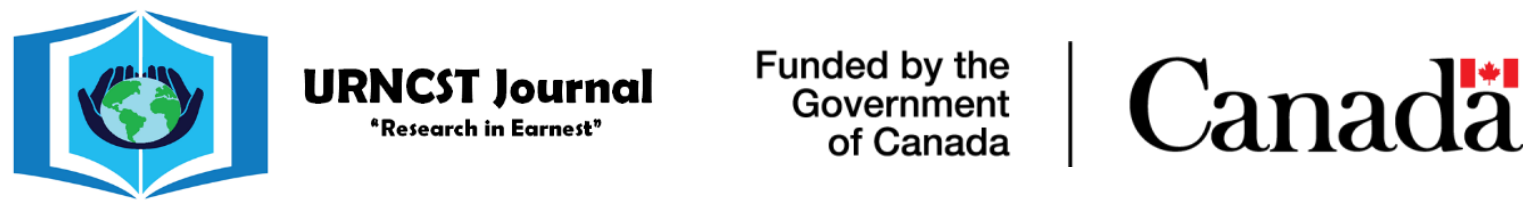

Do you research in earnest? Submit your next undergraduate research article to the URNCST Journal!

| Open Access | Peer-Reviewed | Rapid Turnaround Time | International |

| Broad and Multidisciplinary | Indexed | Innovative | Social Media Promoted |

Pre-submission inquiries? Send us an email at info@ urncst.com | Facebook, Twitter and LinkedIn: @URNCST

Submit YOUR manuscript today at https://www.urncst.com! 